\title{
Expectativas da Avaliação Docente na Educação Superior Brasileira. Um Estudo com os Envolvidos em uma Instituição de Ensino Pública
}

\author{
Expectations for Professor Evaluation in Brazilian Higher \\ Education. A Study with Stakeholders in a Public Institution
}

\author{
Ana Cléa Gomes de Sousa루, Wagner Bandeira Andriola ${ }^{2}$ e Alberto Sampaio Lima*2 \\ ${ }^{1}$ Instituto Federal do Ceará ${ }^{2}$ Universidade Federal Do Ceará
}

\begin{abstract}
Neste artigo apresentam-se os resultados de uma investigação que teve como objetivo analisar as expectativas dos alunos, professores e gestores na avaliação docente de uma instituição de ensino superior. A fundamentação teórica da pesquisa foi baseada em revisão de literatura sobre as dificuldades e potencialidades acerca da temática estudada. No que concerne aos procedimentos metodológicos, além do caráter descritivo, foi adotada a abordagem quali-quantitativa, buscando-se a integração dos dois enfoques por meio da triangulação entre métodos, onde se utilizou da combinação da entrevista semiestruturada com o questionário para a coleta dos dados. Os resultados da pesquisa evidenciaram que há fragilidades no protocolo avaliativo investigado, assim como no cerne das expectativas dos envolvidos encontra-se a urgência de elevar a eficiência do uso dos resultados oriundos da avaliação de professores.
\end{abstract}

Palavras-chave: Avaliação de profesores, Educação superior, Avaliação institucional, Evaliação do ensino.

This article is the result of an investigation which aims analyze the expectations of students, professors and managers in teacher evaluation of an institution of higher education. The theoretical foundation is guided from a literature review addressing the difficulties and potentialities about the topic studied. Regarding the methodological procedures, beyond the descriptive character, the investigation adopted the qualitative and quantitative approach, seeking the integration of the two approaches by triangulation among methods, using the combination of semistructured interviews with the questionnaire to collect data. Results showed that there are weaknesses in the evaluative protocol investigated, well as at the heartwood of stakeholders' expectations is the urgency of raising the efficiency of forms and uses of results from the evaluation of professors based on students' opinions.

Keywords: Professor evaluation, Higher education, Institutional evaluation, Teaching evaluation.

*Contacto: albertosampaio@ufc.br

issn: 1989-0397

www.rinace.net/riee/

https://revistas.uam.es/riee
Recibido: $\quad 18$ de abril de 2016

$1^{\text {a }}$ Evaluación: 23 de junio de 2016

Aceptado: $\quad 5$ de julio de 2016 


\section{Introdução}

A avaliação é um tema de grande relevância para a educação superior, pois está circunscrita na esfera das políticas públicas de educação, efetivando-se como ferramenta estratégica da administração pública no que tange aos processos de fiscalização e promoção da qualidade da educação superior no País (Andriola, 1999). Em consulta à literatura especializada, destacam-se temas recorrentes sobre a temática supramencionada, tais como a questão da autonomia universitária, a vinculação expansão-avaliação-financiamento, a universalização do ensino superior, a avaliação institucional, a qualidade da educação e a avaliação de desempenho docente como suporte para melhoria educacional (Amaral, 2009; Bertolin, 2009; Ristoff, 2011; Sobrinho, 2011; Vaillant, 2008).

De acordo com Lavor, Andriola e Lima (2015), a avaliação dos serviços educacionais de ensino, pesquisa e extensão prestados pelas universidades, é um tema relevante e que contribui para a melhoria da qualidade desses serviços. Para Sobrinho (2011), o fato de os conhecimentos terem passado a ter valor de força produtiva significou mais desafios que soluções para as universidades, que tiveram de ampliar e acelerar as pesquisas em áreas estratégicas para formar recursos humanos capazes de operacionalizar os conhecimentos técnicos. O referido autor assevera que sem autonomia a universidade não poderá realizar-se com qualidade, pois, sem uma critica para produzir conhecimentos e práticas, a universidade estaria fadada a oferecer apenas respostas fragmentadas e imediatistas.

Andriola (2012) e Lima, Andriola e Tavares (2015) asseveram que a aprendizagem consiste no processo através do qual os conhecimentos, as habilidades, as competências, o comportamento observável e os valores são adquiridos ou modificados. Os autores afirmam que o aprendizado é resultado de estudo, experiência, formação, raciocínio e observação, podendo ser analisado a partir de diferentes perspectivas. Alcaraz, Fernéndez Navas e Sola (2012) afirmam que a experiência de avaliação do ensino deve buscar compreender o processo educativo que ocorre nas salas de aula. Os autores afirmam que o ato de avaliar é confuso, e não deve ser confundido com medição ou punição. Dessa forma, os autores recomendaram uma avaliação externa voltada ao desenvolvimento e evolução do sujeito, visando a compreensão e transformação do ensino. Conforme Lima e Andriola (2013), o relato de práticas pedagógicas inovadoras tem ajudado os docentes das instituições de ensino superior, através de uma contribuição para a melhoria do ensino de graduação, com a obtenção de melhores resultados no processo de ensino e aprendizagem.

$\mathrm{Na}$ prática das políticas de avaliação implementadas no Brasil, esteve evidente a existência de um confronto entre duas abordagens metodológicas: a quantitativa e a qualitativa. A primeira salienta a mensuração de desempenho e resultados, a hierarquização das Instituições de Ensino Superior (IES), e orienta-se principalmente para a supervisão do funcionamento institucional. A segunda busca compreender e atribuir significados aos processos e atividades acadêmicas, além de identificar formas para superar fragilidades e desenvolver potencialidades (Bertolin, 2009). Na proposta do atual Sistema Nacional de Avaliação da Educação Superior - SINAES (INEP, 2004), instituído pela Lei 10.861 de 2004, objetivou-se articular aspectos da regulação e da avaliação educativa, esta última numa perspectiva mais formativa e voltada para a 
atribuição de juízos de valor e mérito, tendo em vista o incremento da qualidade e as capacidades de emancipação.

Nesse contexto, Sobrinho (2011) corrobora quando diz que as universidades precisam estar preparadas para renovar e desenvolver os espíritos e as vontades de todos os participantes da comunidade universitária, de forma especial o docente, no seu papel precípuo de facilitar a circulação de ideias, projetos, experiências e programas. Essa perspectiva trata do papel central do docente nos processos educativos, acrescendo-se, sobretudo, os aspectos social e permanente da educação. "A questão pedagógica é a dimensão mais universal e permanente da universidade, por meio da qual esta instituição se distingue das outras". (Sobrinho, 2011a, p. 32).

Desse modo, depreende-se que ações voltadas para avaliação de desempenho docente deverão, sobretudo, fornecer importantes subsídios para a retroalimentação da práxis educativa, dado o sentido pedagógico de todas as atividades desenvolvidas pelos professores nas Instituições de Ensino Superior (IES). Estudos abordam as dificuldades e potencialidades que envolvem a temática supramencionada (Andriola, 2011; Andriola, Andriola, Lima e Silva, 2012; Cisneros-Cohernour e Stake, 2012; Fernandes e Flores, 2012; Flores, 2009; Santo e Santos, 2010; Vaillant, 2008). Ademais, tem sido destacado o papel da gestão estratégica do conhecimento nas Instituições Federais de Ensino Superior (IFES) que, segundo Cavalcante, Cavalcante e Andriola (2010), apresenta limitações, quais sejam: a de informações estratégicas não tratadas e não disseminadas aos tomadores de decisão da universidade, competências individuais e coletivas não exploradas, insuficiente colaboração intraorganizacional e dificuldade de promover o aprendizado coletivo, constituindo-se, portanto, em uma barreira à capacidade de criação e inovação.

Esta pesquisa teve como objetivo geral analisar as expectativas de alunos, professores e gestores no processo de avaliação de desempenho docente no Instituto Federal de Educação, Ciência e Tecnologia do Ceará (IFCE), campus de Sobral, com relação ao uso dos resultados avaliativos para o aprimoramento do ensino. Os resultados obtidos foram promissores, ensejando uma discussão sobre a aplicabilidade dos resultados da avaliação do desempenho docente em instituições de ensino superior (IES).

\section{Revisão de literatura e trabalhos relacionados}

Qual o propósito da avaliação de desempenho docente nas instituições de ensino superior? Dentre os vários desafios da abordagem do tema encontra-se o de definir os fins a que se destina um modelo de avaliação de professores. A complexidade da tarefa é reconhecida por estudiosos da área (Fernandes e Flores, 2012; Graça, Duarte, Lagartixa, Tching e Tomás, 2011; Stronge, 2010; Vaillant, 2008), uma vez que um processo de avaliação docente não é algo anódino, pois seus impactos podem ser extremamente positivos ou negativos. Portanto, há que se considerar, dentre outros aspectos, na avaliação, sua interlocução com a gestão de recursos humanos, pois seus vínculos precisam amparar-se numa lógica de formação contínua, de apoio ao professor na aquisição de competências e de qualificações complementares que possam efetivamente contribuir para a melhoria da aprendizagem dos alunos.

Fernandes e Flores (2012, p. 83), destacam três propósitos que aparecem com maior frequência nos programas de avaliação de professores: (i) influenciar e controlar o 
desempenho dos docentes; (ii) apoiar decisões relacionadas à movimentação docente no sistema; e (iii) legitimar o próprio sistema de controle organizacional.

No primeiro fim, deve- se considerar a complexidade em torno da descrição das funções docentes como fator determinante para que se compreendam as expectativas que envolvem o exercício da profissão. No segundo, vinculam-se avaliação e decisão como premissa para contratação, certificação, promoção ou demissão de professores. Já no terceiro, evidencia-se avaliação como forma de prestar contas às audiências envolvidas, uma vez que tal finalidade busca justificar-se por meio das informações prestadas à comunidade.

Assim, desenvolvimento profissional e prestação de contas na avaliação de professores são propósitos frequentemente descritos como mutuamente exclusivos, destaca Stronge (2010, p. 27). Na perspectiva do autor, as instituições de ensino precisam empreender esforços a fim de estabelecer uma ligação lógica entre estes dois fins. Graça et al. (2011, p. 21) corrobora essa posição ao mencionar desenvolvimento profissional, responsabilização e motivação como os principais objetivos para a avaliação docente.

Convém destacar que para o sucesso de qualquer sistema de avaliação do desempenho, é essencial a existência de três componentes, quais sejam: comunicação, comprometimento organizacional e colaboração, de acordo com Stronge (2010, p. 31). Ocorre que estes três pilares possibilitarão a criação de sinergias que servirão de base para elevar o diálogo em torno dos resultados da avaliação e consequentemente ampliarão as possibilidades de efetiva melhoria da qualidade do ensino:
Uma avaliação que seja conduzida de uma forma superficial, com pouco ou nenhum recurso, usando sistemas de avaliação inválidos e processos de implementação irregulares, acaba por privar a escola, os professores e o público em geral de oportunidades de melhoria e de beneficios que o desenvolvimento profissional e a prestação de contas poderiam, de outra forma, proporcionar. Todos nós, seja qual for nossa relação com o empreendimento educativo, merecemos uma avaliação de elevada qualidade. Qualquer sistema de avaliação que se baseie de forma clara e inequívoca, na melhoria individual e institucional encerra em si a promessa de satisfazer esta necessidade. (Stronge, 2010, p. 40)

Nesse contexto, há que se considerar que a avaliação do desempenho docente é um tema que gera conflito, dada a diversidade de interesses e opiniões de políticos, administradores, docentes e pesquisadores da área. Murillo (2006, p. 13) realizou estudo comparativo analisando a diversidade das propostas e propósitos da avaliação de desempenho docente adotado por países da Europa e America, por meio do qual localizou cinco modelos de avaliação: (i) avaliação do desempenho docente com ênfase na autoavaliação; (ii) avaliação para concessão de licenças; (iii) avaliação como insumo para o desenvolvimento profissional docente, mas sem nenhuma repercussão para a carreira do professor; (iv) avaliação como base para melhorias salariais, e (v) avaliação para a promoção na carreira docente.

Não obstante, Hadji (2010) destaca que a avaliação de professores engloba três grandes funções. A primeira seria de apoio aos docentes e de aconselhamento pedagógico; a segunda, de controle da qualidade do ensino; enquanto a terceira envolveria reconhecimento do mérito para uma eventual promoção. O autor, ao discutir o uso social da avaliação de professores, traz à baila dois grandes fins para a avaliação docente: o de balanço e o de acompanhamento. Dois pontos preponderantes na discussão devem ser considerados. Primeiro, a concepção clássica da função de controle que busca garantir a conformidade com uma norma. Segundo, a perspectiva mais moderna de controle que o 
coloca como elemento central de uma regulação destinada a aperfeiçoar um determinado funcionamento (Hadji, 2010, pp. 121-130).

Assim sendo, como fazer uso dos resultados da avaliação de professores para efetivamente melhorar o ensino? Responder tal indagação não é tarefa fácil, sobretudo quando se trata de um modelo baseado na opinião dos estudantes. Cisneros-Conhenour e Stake (2010, p. 221) dizem que o desempenho é a base intencional para as avaliações do ensino realizadas pelos alunos. Para os autores, o desempenho é usualmente mais importante que as competências, pois estas seriam potenciais, sendo que sua importância reside no momento da contratação do profissional; porém, não são tão valiosas para avaliar o trabalho realizado. Já o desempenho é geralmente mais importante, uma vez que a ação realizada, em certa situação, é usada como base para qualificar o trabalho de uma pessoa.

Cisneros-Conhenour e Stake (2012, p. 48), em pesquisa realizada sobre o uso dos resultados da avaliação para melhorar as práticas pedagógicas, discutem, dentre outros aspectos, o proveito do feedback e destacam a importância de se acrescentar às avaliações realizadas pelos alunos outras fontes de informação. É patente, na perspectiva dos autores, que os estudantes são vistos como uma fonte acessível em relação às avaliações efetivadas por pares ou por um especialista. Há que se considerar, portanto, os riscos no que tange ao uso dos resultados da avaliação de desempenho docente baseado na opinião dos estudantes. O uso de notas atribuídas pelos alunos aos professores para os propósitos formativo e somativo pode resultar na violação da liberdade acadêmica do professor e diminuir a qualidade do ensino (Cisneros-Conhenour e Stake, 2012, p. 49). Nesse sentido, Murillo (2006, p. 59) reforça a discussão ao mencionar, em seu estudo, que os sistemas de avaliação de desempenho docente possuem dois propósitos básicos: melhorar e assegurar a qualidade do ensino e tomar alguma decisão a respeito do docente. Trata-se, portanto, das perspectivas formativa e somativa da avaliação, respectivamente.

Stronge (2010) advoga por uma avaliação do desempenho docente documentada com base em múltiplas fontes de informação. "O fato de os alunos serem os principais clientes do serviço docente constitui um argumento válido para os envolver no próprio feedback de avaliação" (Stronge, 2010, p. 36). Hadji (2010, p. 128) alerta para o fato de que todo o trabalho de avaliação deve orientar-se para o uso social dos seus resultados. Ao discutir propostas para uma evolução positiva das práticas avaliativas e, por conseguinte, evitar desvios no uso dos resultados da avaliação, Hadji (2010, pp. 135-137) propõe quatro pistas operatórias: transparência, continuidade, olhares cruzados e considerar os resultados da investigação.

Considerando as proposições dos autores, infere-se que uma instituição, antes de fazer uso dos resultados de uma avaliação de desempenho docente, seja para propósitos formativo e/ou somativo, precisa previamente definir, além dos fins, o que efetivamente está sendo avaliado, ou seja, que competências são requeridas do docente para então avaliar seu desempenho, sobretudo quando pretende tomar como principal fonte de informação os estudantes.

Evidenciou-se, na literatura consultada, que não há consenso entre os estudiosos acerca da validade conceitual e das consequências de avaliações baseadas na opinião discente. Para Fernandes e Flores (2012, p. 87), a avaliação dos alunos tem sido considerada um indicador válido do desempenho, constituindo-se como uma medida de satisfação direta 
relativamente ao ensino ministrado. Já (Stake, 1995 apud Stake, 2008, p. 25) enfatiza que o desempenho é, às vezes, companheiro de um bom ensino, mas um indicador questionável deste.

A literatura internacional demonstra a complexidade do tema em estudo, mas também revela que há razões para afirmar que a avaliação de desempenho docente pode dar suporte para melhorar a educação (Fernandes e Flores, 2012; Vaillant, 2008). Assim, advoga-se pela relevância das experiências de avaliações de professores baseadas na opinião de estudantes, bem como acredita-se que os resultados das avaliações devem, $a$ priori, retroalimentar a práxis educativa dos professores (propósito formativo), mas, também, precisam gerar consequências (propósito somativo).

\section{Metodologia}

O objetivo geral da presente pesquisa foi analisar as expectativas dos alunos, professores e gestores na avaliação docente em uma instituição de ensino superior, no caso o Instituto Federal de Educação, Ciência e Tecnologia do Ceará (IFCE), localizado no estado do Ceará, Brasil.

A metodologia adotada contemplou a avaliação dos atores do processo. Um estudo de caso foi realizado em uma IES. Pelo fato da natureza da investigação avaliativa ter abordado as opiniões dos envolvidos acerca da atuação dos professores, empregou-se na avaliação o método ex post-facto (Bisquerra, 2004), também conhecido como método estatístico (Gil, 2009).

O estudo realizado obedeceu os seguintes passos:

1. Validação da problemática;

2. Revisão de literatura;

3. Planejamento e validação do instrumento de pesquisa;

4. Aplicação dos questionários;

5. Tabulação e análise dos resultados;

6. Publicação dos resultados.

Considerando a complexidade do objeto decidiu-se associar a pesquisa qualitativa com a quantitativa em um único plano de estudo, sendo que os métodos qualitativos precederam os quantitativos, uma vez que a integração das duas abordagens, de acordo com as proposições de Flick (2009, p. 43), efetivou-se por meio das seguintes etapas: (i) uma entrevista semiestruturada, (ii) estudo de questionário como etapa intermediária e (iii) aprofundamento e avaliação de resultados obtidos. Quanto à abordagem do problema, considera-se quali-quantitativa, pois foi procedida a integração entre as duas abordagens por meio de triangulação entre métodos, já que a base dessa concepção é "[...] o insight lentamente estabelecido de que métodos qualitativos e quantitativos devem ser vistos como campos complementares" (Flick, 2009, p. 43). Quanto aos objetivos é descritiva porque seu objetivo é a descrição das características de determinada população ou fenômeno, assim como pela possibilidade de se estabelecer relações entre as variáveis (Flick, 2009; Gil, 2009).

A população da instituição investigada, descrita na tabela 1, constitui-se de 1.093 indivíduos entre alunos, professores e gestores. 
Tabela 1. População da pesquisa

\begin{tabular}{lcc}
\hline \multicolumn{1}{c}{ CARACTERÍSTICA DOS RESPONDENTES } & POPULAÇão & AMOSTRA \\
\hline Discentes & 1.043 & 281 \\
Docentes/Gestores & 50 & 50 \\
\hline Total & 1.093 & 331 \\
\hline
\end{tabular}

Fonte: Relatório da Diretoria de Ensino (IFCE, 2012).

Com relação ao conjunto de professores e gestores, a pesquisa foi censitária, já com relação aos discentes, estudou-se uma amostra probabilística estratificada, uma vez que o principal objetivo dessa técnica de amostragem é aumentar a precisão da pesquisa (Malhotra, 2011, p. 281).

Com relação à validade interna do questionário procedeu-se à análise da estrutura fatorial dos instrumentos da presente investigação, com vistas a verificar sua adequação. No teste de viabilidade do instrumento destinado aos docentes, foi obtido 0,93 no Teste de Kaiser-Meyer-Olkin (KMO) com significância < 0,01 no Teste de Esfericidade, de Bartlett. Fez-se a análise fatorial utilizando o método dos componentes principais e três fatores destacaram-se dos demais, obtendo autovalor (eigenvalue) de 5,25, 4,60 e 3,15, respectivamente, com bom poder de representação, pois, em conjunto, conseguiram explicar $28,93 \%$ da variância total dos resultados. Já com relação ao questionário destinado aos discentes, obteve-se o resultado 0,88 no Teste de Kaiser-Meyer-Olkin (KMO), com significância < 0,01 no Teste de Esfericidade, de Bartlett. Quatro fatores destacaram-se dos demais, obtendo autovalor (eigenvalue) de 5,81, 2,71, 2,66 e 2,01, respectivamente, com bom poder de representação, pois, em conjunto, conseguiram explicar $28,70 \%$ da variância total dos resultados.

$\mathrm{Na}$ análise da precisão dos instrumentos, foi aplicado o coeficiente alpha de Lee Cronbach. $\mathrm{O}$ valor obtido para o questionário destinado aos docentes foi de 0,75 para os 45 itens avaliados. Com relação ao instrumento direcionado aos discentes, obteve-se 0,73 para os 46 itens. Portanto, considera-se que os resultados demonstram a qualidade das variáveis que compuseram os instrumentos de investigação em relação ao que se pretende avaliar.

Convém destacar que não foi registrado durante o percurso dessa pesquisa recusa por parte dos alunos e/ou dos professores de contribuir com a investigação. A aplicação dos questionários ocorreu de acordo com as seguintes etapas: (i) contato por telefone e/ou email com antecedência com os docentes para solicitação de autorização e devido consenso do melhor dia/horário para visita da pesquisadora à sala de aula; (ii) na abordagem aos alunos, explicitaram-se os objetivos da pesquisa, bem como garantiu-se a confidencialidade com relação à identificação dos respondentes; (iii) os professores foram solicitados a responder o instrumental de forma simultânea aos alunos em todas as salas. Apesar de haver sido realizado sorteio prévio dos alunos que comporiam a amostra, aplicou-se o questionário com todos os alunos presentes na sala durante a visita, abordando quatro blocos temáticos.

A análise e discussão dos resultados deu-se por meio de quatro bloco temáticos. $\mathrm{O}$ primeiro versa sobre a divulgação dos resultados e a finalidade do processo avaliativo (BTI); o segundo discute o instrumento de avaliação e o contex to do trabalho docente 
(BTII); o terceiro discorre sobre a influência do feedback na prática docente (BTIII) e o quarto apresenta o vínculo entre o processo avaliativo e as decisões institucionais (BTIV).

\section{Estudo de caso}

O SINAES estabelece dez dimensões institucionais norteadoras para a autoavaliação nas IES, sendo que a dimensão de número dois (política institucional voltada para o ensino, à pós-graduação, à pesquisa e à extensão) analisa, dentre outros aspectos, as práticas pedagógicas institucionais que estimulam a melhoria do ensino, a formação docente, o apoio ao estudante, a interdisciplinaridade e as inovações didático-pedagógicas. A partir da compreensão do SINAES como forma de assegurar a melhoria da qualidade da educação superior, definiu-se a seguinte problemática: Que expectativas possuem os envolvidos no processo de avaliação de desempenho docente no Instituto Federal do Ceará, campus de Sobral, com relação ao uso dos resultados avaliativos para o aprimoramento do ensino?

Dessa forma, buscou-se identificar os limites e as possibilidades na efetivação da experiência de avaliação de desempenho docente vivenciada no Instituto Federal de Educação, Ciência e Tecnologia do Ceará (IFCE), campus de Sobral. A discussão aborda a razão de ser da docência, no contexto da avaliação do desempenho no ensino superior, levando em consideração o uso que se faz dos resultados como fator determinante da cultura avaliativa estabelecida e sua interlocução com as expectativas dos envolvidos no processo, uma vez que “[...] o uso que se faz dos resultados da avaliação dos professores determina o que se avalia e o modo como se avalia” (Fernandes e Flores, 2012, p. 83).

\section{Análise dos resultados}

A partir dos resultados obtidos durante o estudo realizado, são apresentados e avaliados na sequência, os principais pontos identificados.

\subsection{Divulgação dos resultados e finalidade do processo avaliativo}

No que tange aos aspectos 2.1, 2.2, 2.3 e 2.9, houve uma predominância de assertivas negativas na avaliação dos alunos, consignadas na figura 1, revelando que as formas utilizadas para divulgar os resultados pela instituição apresentam limitações.

Destaca-se ainda a confluência de opinião na avaliação dos docentes e discentes em relação às variáveis 2.1 e 2.3 (figura 2). Como se percebe, há indicativo de fragilidade nos procedimentos adotados para esclarecer a comunidade discente sobre a finalidade da Avaliação de Desempenho Docente (ADD), uma vez que uma única visita às salas de aulas dos ingressantes foi avaliada como ineficiente $(60,50 \%)$, fato também constatado nos resultados apurados para os itens 2.2 e 2.3 (56,94\% e $54,10 \%$, respectivamente), que apontam desconhecimento das formas adotadas para divulgação dos resultados da ADD. 


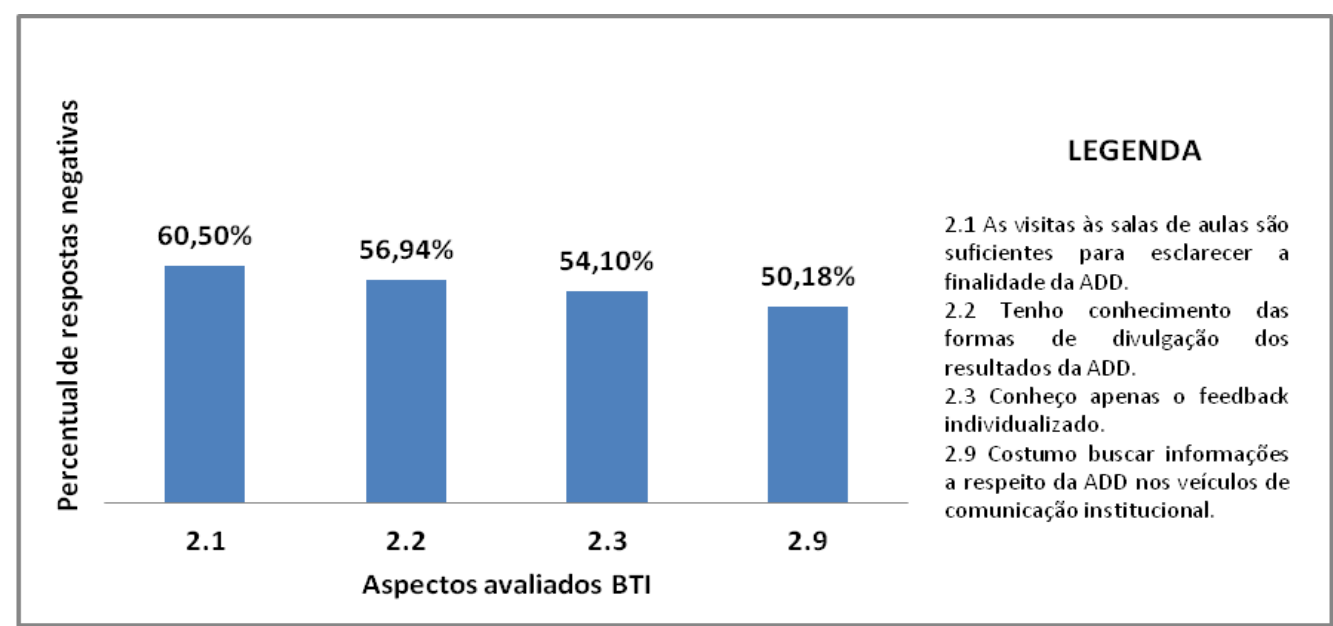

Figura 1. Asserções negativas na avaliação discente quanto aos resultados e processo avaliativo

Fonte: Elaboração própria.

A figura 2 aponta que $72 \%$ dos professores conheciam apenas o feedback individualizado fornecido aos docentes ao final de cada ciclo avaliativo, revelando, portanto, desconhecimento da existência de outros documentos que visam orientar as condutas do grupo gestor frente ao corpo docente, como, por exemplo, o relatório anual com informações gerais consolidadas a partir da ADD.

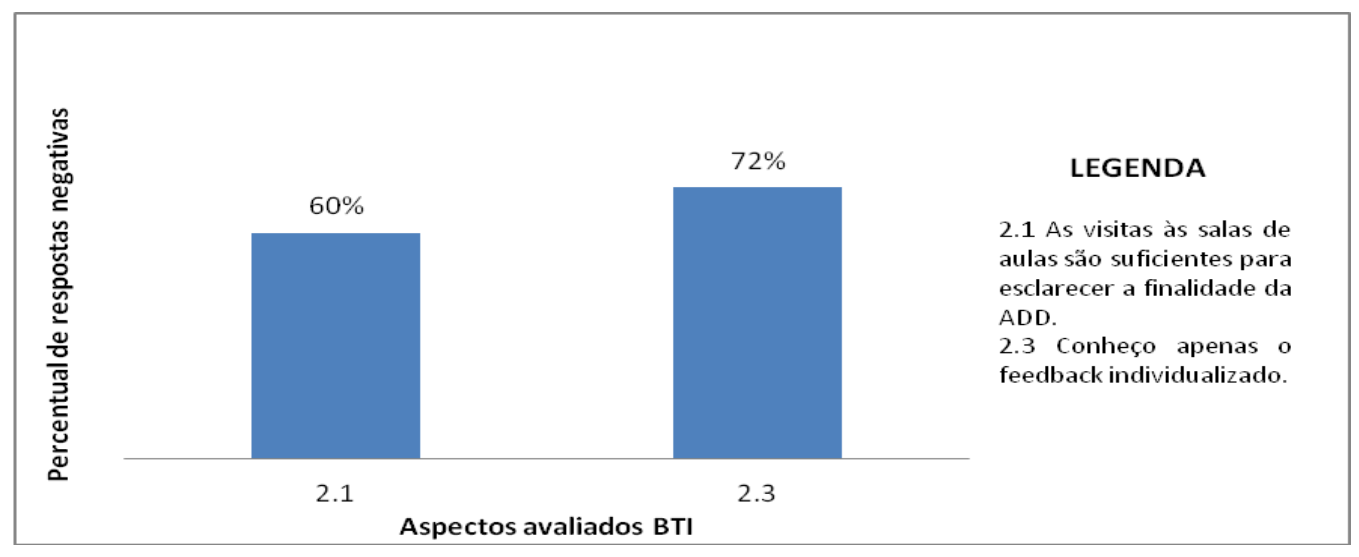

Figura 2. Asserções negativas na avaliação docente quanto aos resultados e processo avaliativo

Fonte: Elaboração própria. 


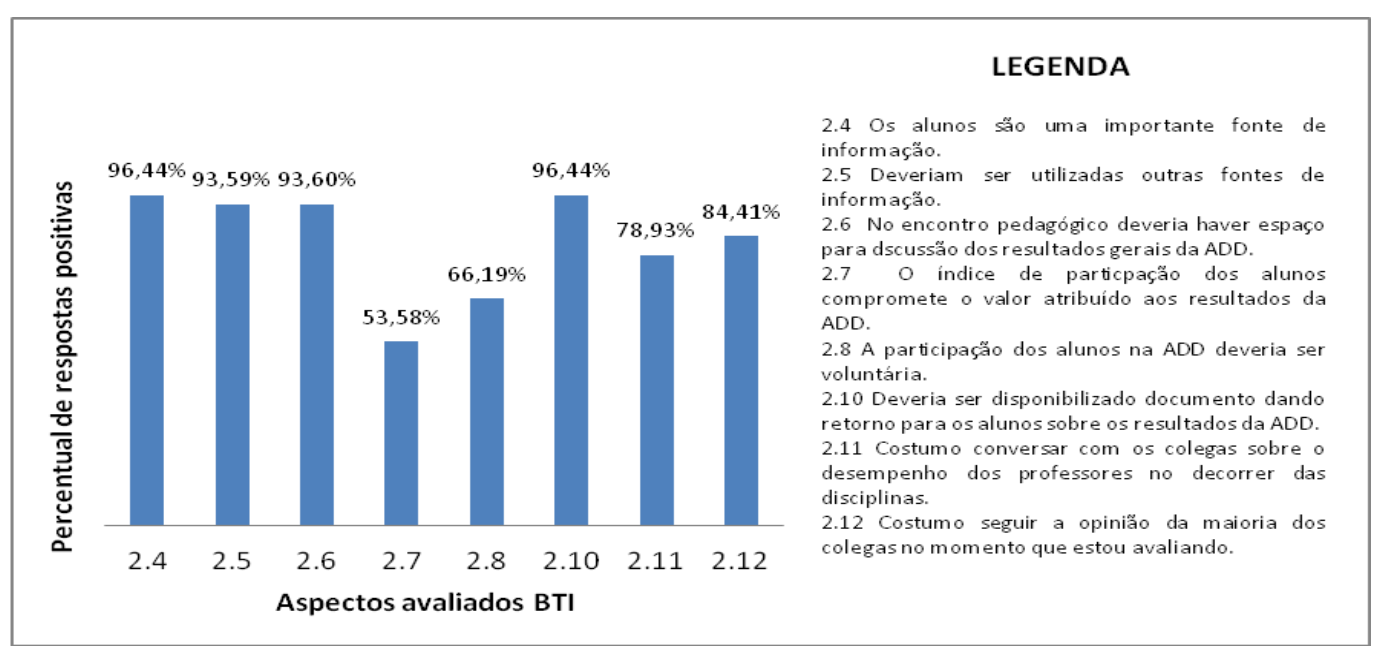

Figura 3. Asserções positivas na avaliação discente quanto aos resultados e processo avaliativo

Fonte: Elaboração própria.

Na figura 3, através dos resultados obtidos para as variáveis 2.4, 2.5, 2.6, 2.7, 2.8, 2.10, 2.11 e 2.12, identificaram-se aspectos positivos, dentre os quais convém destacar o autorreconhecimento do corpo discente como importante fonte de informação para avaliar a consecução do trabalho docente (96,44\%, na variável 2.4), mesmo patamar alcançado na avaliação docente (figura 4).

Conforme se vê nas Figuras 3 e 4, mais da metade dos respondentes reconhecem a importância da participação dos alunos nas avaliações semestrais (variável 2.7), enfatizando que o desinteresse do discente em participar da ADD poderá comprometer o valor atribuído aos resultados. Ressalvam, entretanto, que a adesão discente deve ser voluntária (variável 2.8), com índices acima de 60\%.

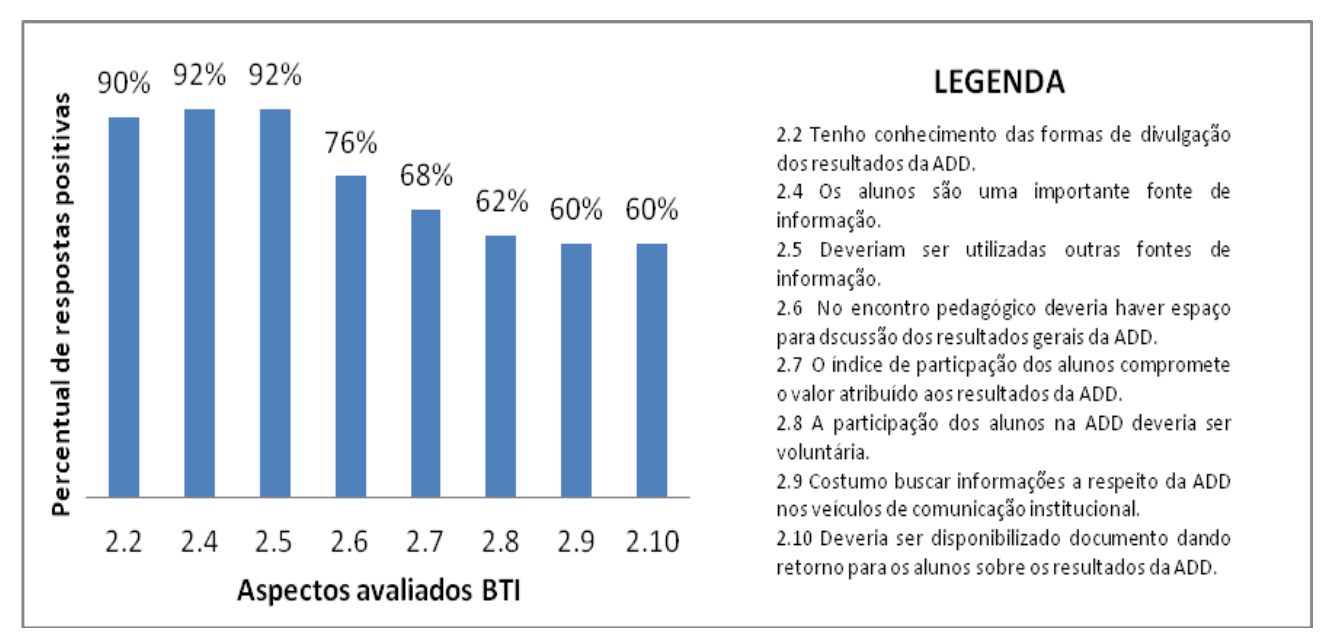

Figura 4. Asserções positivas na avaliação docente quanto aos resultados e processo avaliativo

Fonte: Elaboração própria. 
As mesmas figuras 3 e 4 destacam, ainda, a convergência de opinião entre professores e alunos no que tange à busca de informação sobre o processo avaliativo através dos veículos oficiais de comunicação com a comunidade acadêmica (variável 2.9), reconhecendo-se, inclusive, a necessidade de se fornecer aos discentes feedback sobre os resultados da ADD (variável 2.10). Revelou-se, também, que os alunos costumam conversar sobre o desempenho dos professores (variável 2.11 - índice de 78, 93\%) durante o decorrer das disciplinas, mas esse fato não significa, na perspectiva discente, que as opiniões individualizadas sejam influenciadas por outros colegas, visto que, na variável 2.12, 84,41\% dos respondentes afirmam que não costumam seguir opiniões divergentes de colegas no momento da avaliação dos professores.

No período de 2009 a 2012, a instituição vivenciou oito ciclos avaliativos e, embora estejam manifestas nos dados ora apresentados as limitações no que tange à divulgação dos resultados e a forma como têm sido expressas a finalidade e as dimensões avaliadas para os alunos novatos, haja vista este item ter obtido maior percentual na figura 1 $(60,50 \%)$, identificou-se, nas figuras 3 e 4 , expectativas dos respondentes que, uma vez atendidas, poderão contribuir para o fortalecimento das fragilidades identificadas na dimensão investigada. Espera-se: (i) inserir no encontro pedagógico espaço para discussão dos resultados da avaliação de desempenho docente; (ii) utilizar outras fontes de informações acerca da consecução da atividade docente para acréscimo àquelas fornecidas pelos alunos; (iii) fornecer feedback aos alunos acerca dos resultados da avaliação de desempenho docente; (iv) excluir a obrigatoriedade de participação dos alunos nas avaliações de desempenho docente.

\subsection{Instrumento de avaliação e o contexto do trabalho docente}

$\mathrm{Na}$ análise das variáveis 3.1, 3.2 e 3.3, consignadas na figura 5, observou-se a confluência de opiniões na perspectiva dos professores e dos alunos no que tange, respectivamente, à necessidade de inserir informações complementares no questionário utilizado para avaliar o corpo docente (alunos: 71,53\%; professores: 92\%); ao fato do desempenho discente na disciplina cursada representar fator de influência quando os alunos estão avaliando os professores (alunos: 65,83\%; professores: 72\%) e à utilização dos fatos mais recentes ocorridos na sala como parâmetro para avaliar os professores (alunos: 72,60\%; professores: $74 \%)$.

Infere-se que a atual prática da instituição em estudo, cuja avaliação possui caráter somativo, contribuiu para as asserções negativas obtidas, uma vez que os respondentes demonstraram expectativa de inserção de uma avaliação formativa, conforme resultado obtido na variável 3.4, expresso nas figuras 7 e 8 .

$\mathrm{Na}$ análise da variável 3.5, que corresponde à valoração atribuída pelos discentes às questões abertas contidas no questionário, constatou-se que metade dos respondentes da amostra discente atribui maior valoração às notas atribuídas aos professores do que a relatos, destacando aspectos positivos e/ou negativos acerca da ação docente durante as aulas. Ressalta-se que 59,43\% dos alunos (variável 3.10) consideraram desnecessário iniciar a ADD com questões abertas, uma vez que tal iniciativa, na perspectiva discente, não representaria um estímulo para ampliar o número de relatos efetivados nos ciclos avaliativos. No entanto, comparando-se com o censo realizado com os docentes, encontra-se uma divergência, pois 54\% destes (variável 3.10 - figura 8) consideraram necessário iniciar a ADD com questões abertas. 


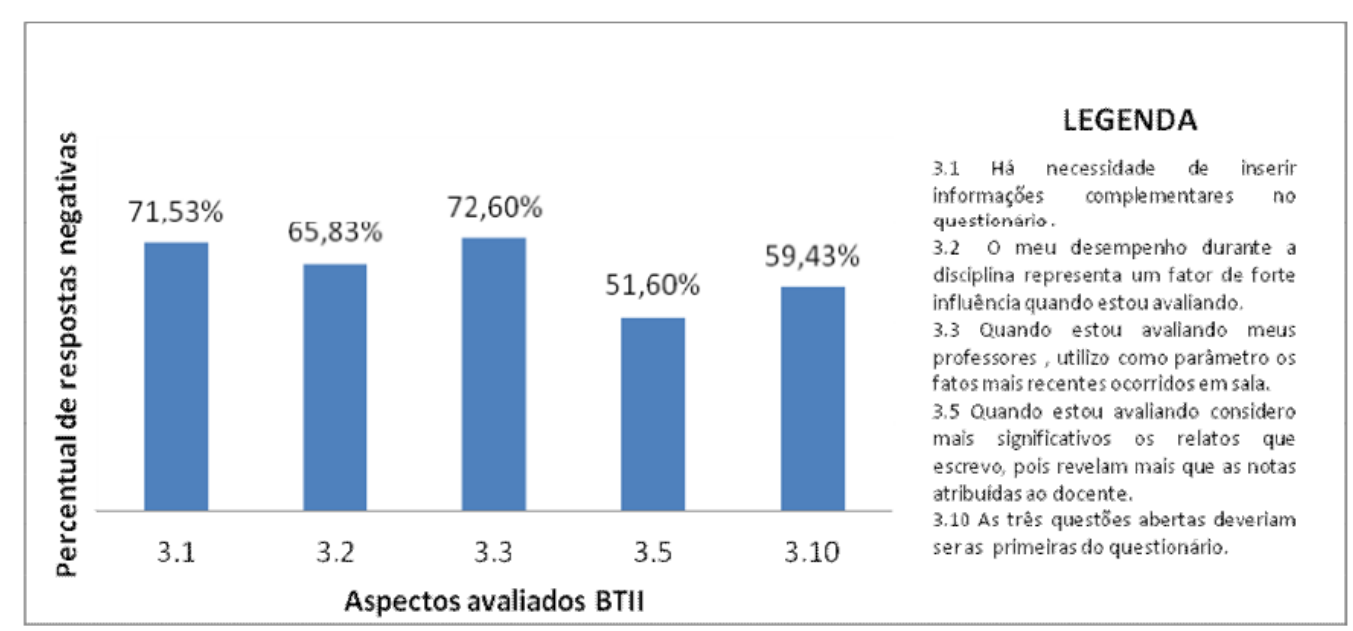

Figura 5. Asserções negativas na avaliação discente sobre o instrumento utilizado Fonte: Elaboração própria.

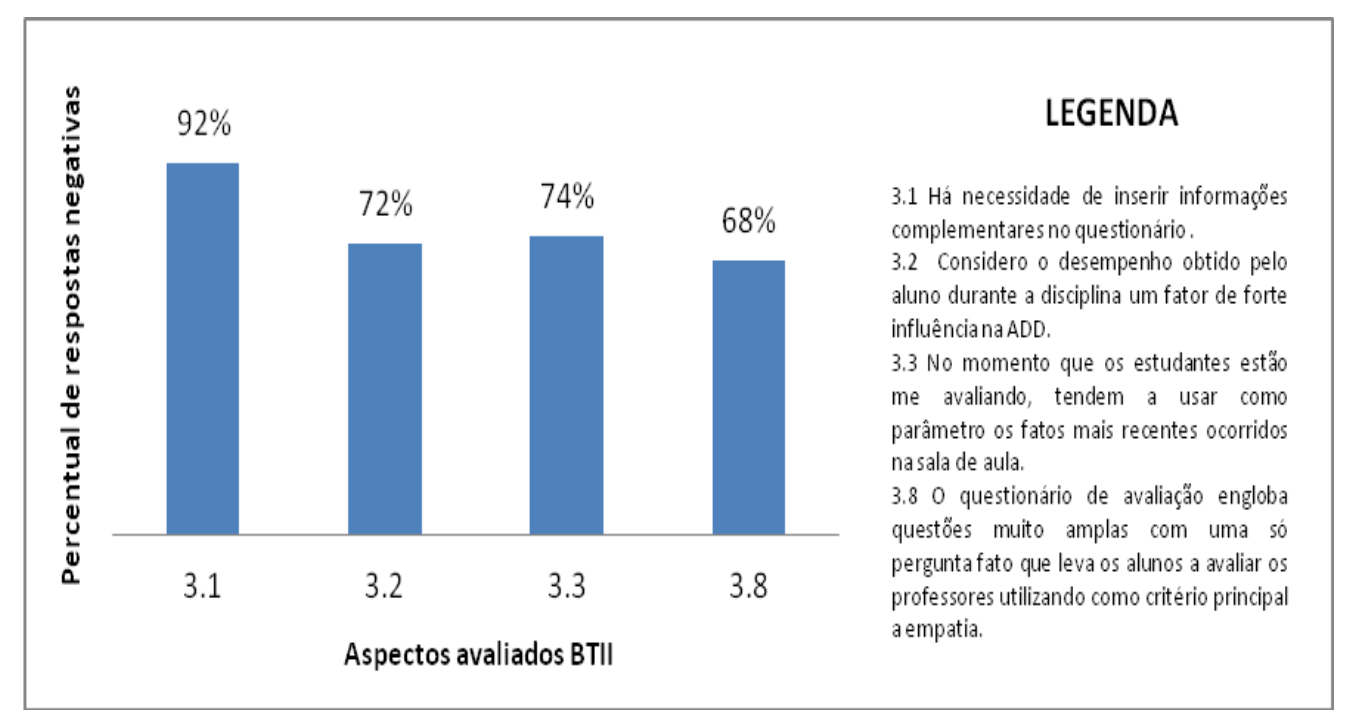

Figura 6. Asserções negativas na avaliação docente sobre o instrumento utilizado Fonte: Elaboração própria.

Outro ponto de discordância relaciona-se à análise da variável 3.8 (figuras 6 e 7), que corresponde à avaliação dos itens que compõem o questionário usado para avaliar os professores. Dos docentes, $68 \%$ consideraram que os itens que compõem o instrumento usado na ADD englobam questões amplas e que tal característica poderá induzir os alunos a avaliarem seus professores utilizando como principal critério a empatia; enquanto, $69,40 \%$ dos estudantes discordaram de tal afirmativa. Nas figuras 7 e 8 , visualizam-se as proposições positivas dos respondentes.

Através da análise dos resultados obtidos nas variáveis 3.4, 3.6, 3.7 e 3.9, identificou-se convergência nas asserções dos respondentes por meio das quais se conheceu as expectativas dos respondentes, no que diz respeito à ferramenta utilizada para avaliar o desempenho dos professores, dentre elas: (i) implantar ciclos de ADD ancorados numa perspectiva formativa de avaliação; (ii) inserir no questionário espaço para autoavaliação discente; (iii) inserir perguntas norteadoras para subsidiar a avaliação dos alunos, uma 
vez que os itens do questionário foram considerados suficientes para contemplar os pontos principais do trabalho docente.

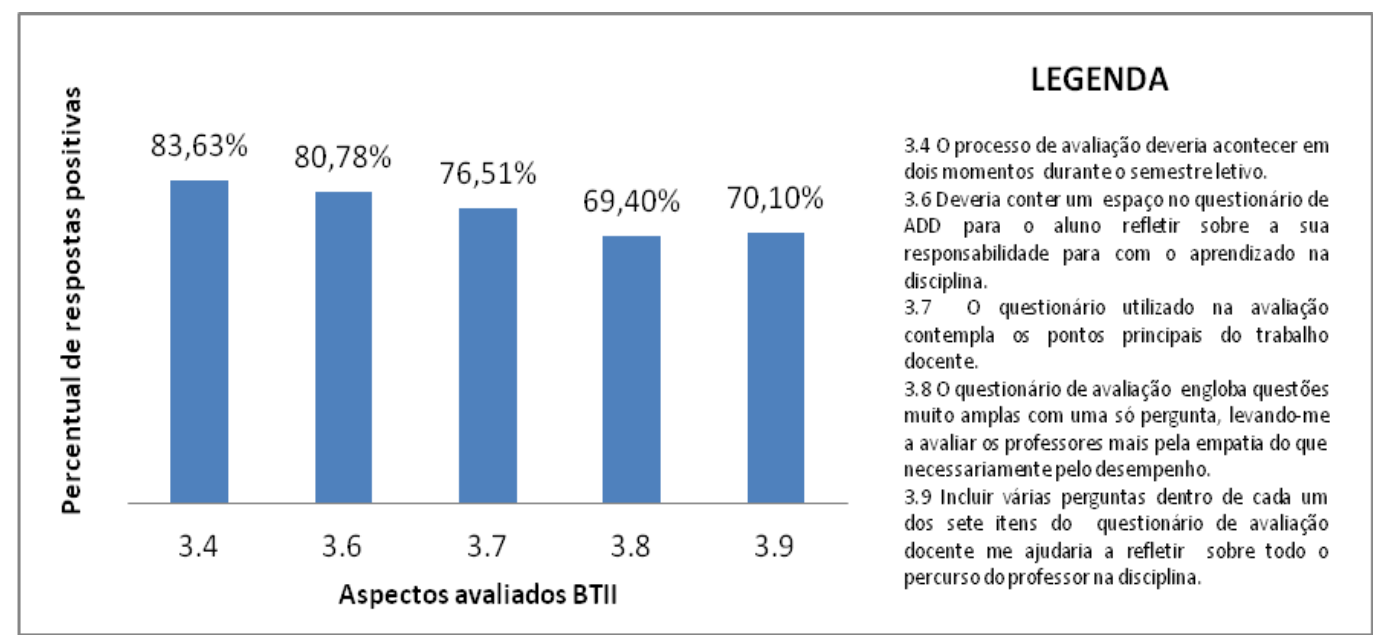

Figura 7. Asserções positivas na avaliação discente sobre o instrumento utilizado

Fonte: Elaboração própria.

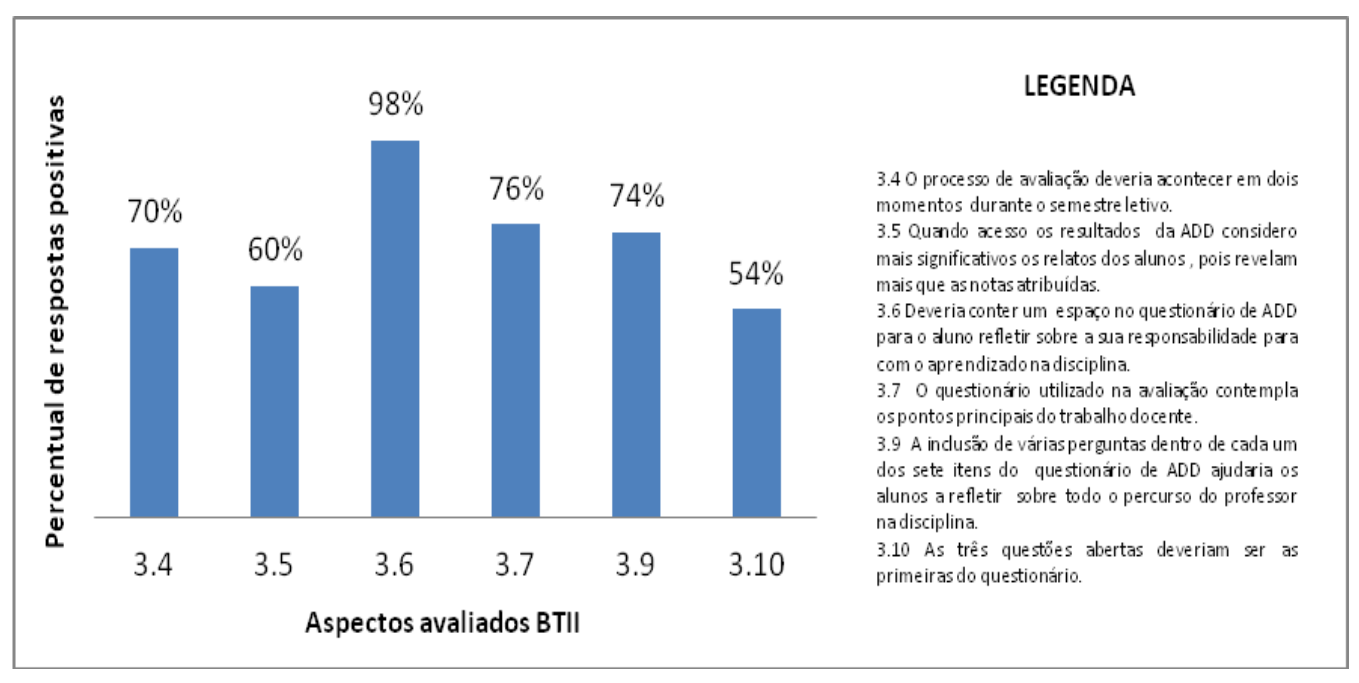

Figura 8. Asserções positivas na avaliação docente sobre o instrumento utilizado

Fonte: Elaboração própria.

Com relação à variável 3.10, como mostra a figura 8, 54\% dos professores consideraram que as questões abertas deveriam ser as primeiras, pois tal medida estimularia os alunos a fazerem relatos. Em consulta aos relatórios emitidos pela Diretoria de Ensino, constatou-se que no período de 2009 a 2012, apesar da resistência dos discentes em expressar suas opiniões acerca da ação docente durante os ciclos avaliativos, houve um considerável aumento no número de relatos na ADD. Ainda que os resultados tenham revelado que os discentes subestimam as questões abertas em comparação às fechadas do instrumental utilizado pela unidade de ensino em análise, ainda assim considera-se relevante a existência de tais questões, uma vez que os professores valoraram positivamente tal característica do questionário adotado. 
Convém destacar a importância dos relatos discentes na retroalimentação da prática docente, pois, considerando o caráter somativo do protocolo avaliativo adotado pela instituição, talvez essa característica do questionário tenha representado para o professor uma possibilidade ímpar de repensar sua ação pedagógica (para o semestre subsequente), referendando-se nas leituras e inferências que os relatos possibilitam, uma vez que oportunizam para as partes envolvidas um espaço aberto para críticas, elogios e sugestões no âmbito e para além dos sete indicadores ${ }^{1}$ que compõem o instrumento adotado na ADD da instituição investigada.

\subsection{Influência do feedback na prática docente}

$\mathrm{Na}$ análise do aspecto 4.2 (figuras 9 e 10), observou-se confluência de opinião na avaliação dos respondentes, apurando-se que $60 \%$ dos professores e $77,23 \%$ dos alunos expressaram que o corpo docente não comenta com os estudantes sobre o feedback recebido acerca dos resultados da ADD.

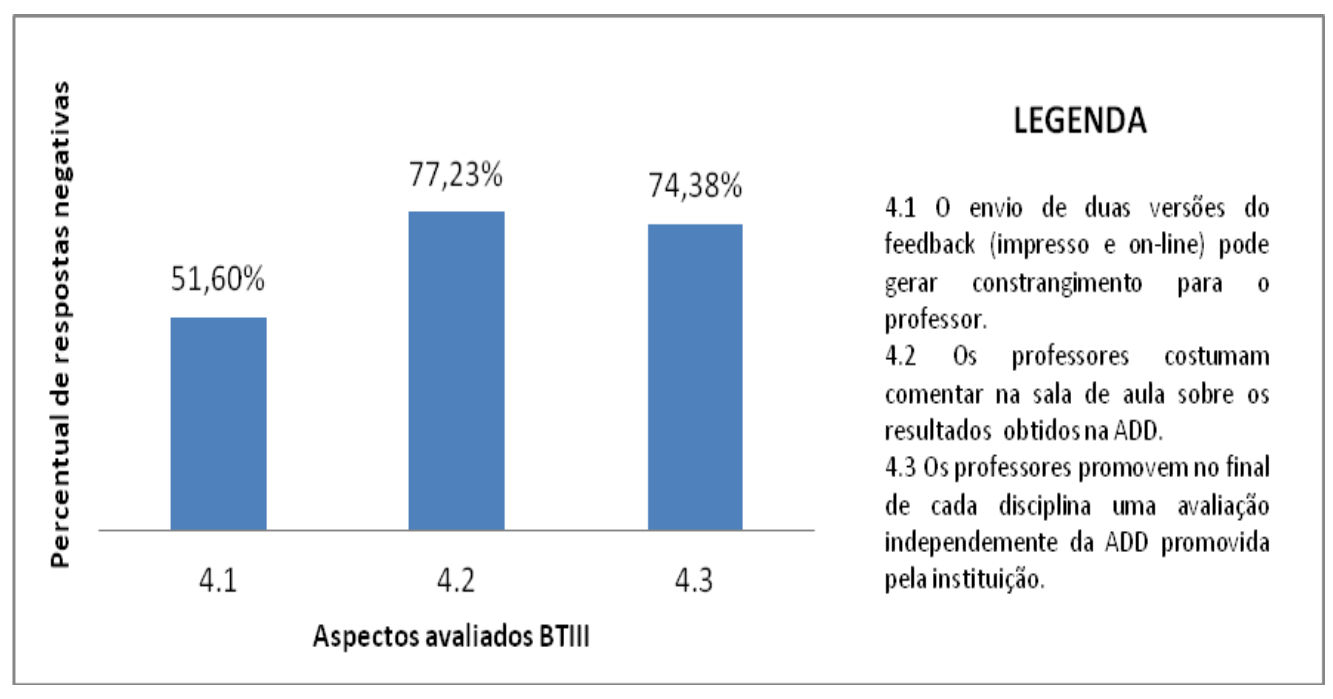

Figura 9. Asserções negativas na avaliação discente sobre o feedback individualizado para melhoria da prática docente

Fonte: Elaboração própria.

Depreende-se que o fato de os professores receberem os resultados avaliativos somente no início do semestre subsequente àquele ao qual foram avaliados pode ter contribuído para a postura dos docentes, pois, numa perspectiva somativa de avaliação, o educador poderá não encontrar espaço adequado para comentar sobre o feedback recebido, uma vez que encontra-se com outra turma.

O item 4.1 investigou se o fato de os professores receberem duas versões dos resultados de um mesmo período avaliativo (impresso e on-line) poderia gerar constrangimento para o docente. Da amostra discente, $51,60 \%$ concordaram com tal afirmativa, enquanto $92 \%$ dos professores (figura 12) discordaram. Trata-se, portanto, de uma divergência de

${ }^{1}$ Indicadores que compõem o questionário de ADD do IFCE, campus de Sobral: assiduidade, pontualidade, domínio de conteúdo, metodologia de ensino, relação professor-aluno, incentivo a participação do aluno e avaliação. 
opinião. O mesmo foi observado na análise da variável 4.3, que investigou se os professores promoveram, ao final de cada disciplina, momentos de avaliação independentes daquele conduzido pela instituição. Constatou-se que 74,38\% dos alunos discordaram de tal proposição. Convém destacar que 50\% dos professores concordaram com a assertiva do item 4.3, enquanto a outra metade discordou, ou seja, uma situação de igualdade de opiniões no censo realizado, motivo pelo qual decidiu-se omitir essa variável da figura 12. Os resultados, bem como a divergência de opiniões observada na variável em questão, revelaram fragilidade no que tange às práticas de autoavaliação no âmbito das disciplinas ministradas pelos professores da Instituição de Ensino Superior (IES) em estudo.

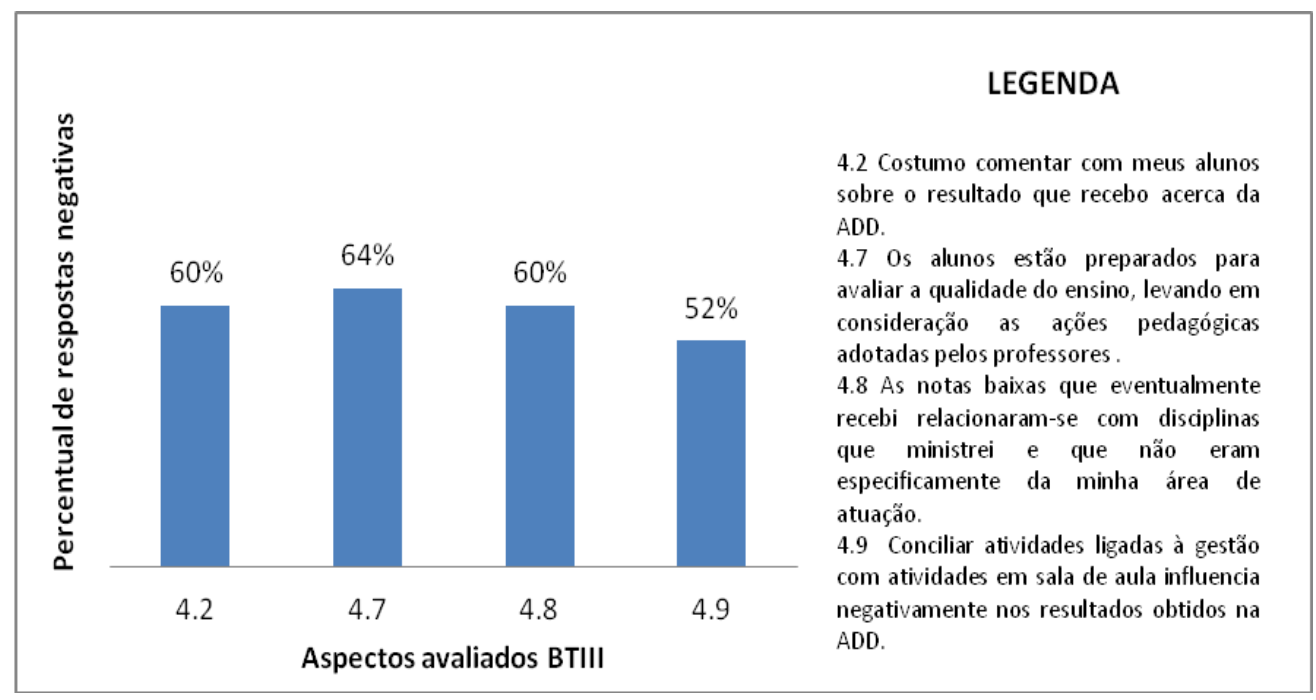

Figura 10. Asserções negativas na avaliação docente sobre o feedback individualizado para melhoria da prática docente Fonte: Elaboração própria.

A variável 4.7 investigou se os professores consideram os alunos preparados para avaliar a qualidade do ensino levando em consideração as ações pedagógicas adotadas pelo educador. Essa mesma proposição foi investigada no questionário aplicado com os alunos através do item 4.6 (figura 11). Conforme se vê na figura 10 acima, $64 \%$ dos professores discordaram da afirmativa 4.7. Para $85,76 \%$ da amostra discente, os estudantes consideram-se preparados para avaliar os educadores. Portanto, constata-se que parte da comunidade docente ainda concebe com desconfiança avaliações referendadas na opinião discente, embora um índice significativo dos respondentes tenha considerado que os alunos são uma importante fonte de informação para avaliar a consecução da atividade docente (item 2.4 figuras 3 e 4 do BTI). Dentre as múltiplas fontes citadas pelos entrevistados para avaliar o desempenho docente, merecem destaque as seguintes:

$\checkmark$ Segundo os discentes: (i) alunos e autoavaliação (35\%); (ii) alunos, autoavaliação e avaliadores externos (27\%) e (iii) apenas os alunos (15\%);

$\checkmark$ Segundo os docentes: (i) alunos e autoavaliação (38\%); (ii) alunos, avaliadores externos, pares e autoavaliação $(22 \%)$ e (iii) alunos, pares e autoavaliação $(18 \%)$. 
Portanto, identificou-se convergência na opinião dos respondentes, uma vez que estes valoraram que os alunos e a autoavaliação, juntos, são fontes consideradas significativas para retroalimentar a prática do professor e, por conseguinte, contribuir para a melhoria do ensino.

$\mathrm{Na}$ análise da variável 4.8, que investigou se as notas baixas recebidas na ADD relacionaram-se com disciplinas ministradas pelos professores, as quais não eram das suas respectivas áreas de atuação, constatou-se que $60 \%$ dos professores concordaram com a assertiva desse item, demonstrando ser este, na avaliação docente, um fator a ser considerado frente aos resultados negativos obtidos ao longo dos ciclos avaliativos. Porém, 58,01\% dos discentes discordaram dessa proposição (no questionário aplicado com os docentes, a variável 4.8, figura 10 , corresponde ao conteúdo do item 4.7, figura 11).

A influência negativa de atividades ligadas à gestão quando conciliadas com atividades docentes foi investigada através da variável 4.9. Para $52 \%$ dos professores, os resultados da ADD são influenciados negativamente quando um docente assume um cargo de confiança. A mesma proposição foi colocada no questionário dos alunos no item 4.8 (figura 11), em que 56,59\% não concordaram com tal afirmativa. Diante da discordância de opiniões, convém destacar que, na IES em foco, quando um professor assume cargo de gestão, há redução na carga horária semanal de disciplinas a serem ministradas nos cursos. Ao assumir uma coordenadoria de eixo tecnológico, por exemplo, um professor tem sua carga horária máxima de atividades docentes em sala de aula reduzida de 24 horas para 8 horas semanais, de acordo com a Resolução $\mathrm{n}^{\circ}$ 34, de 02 de setembro de 2010, do Conselho Superior.

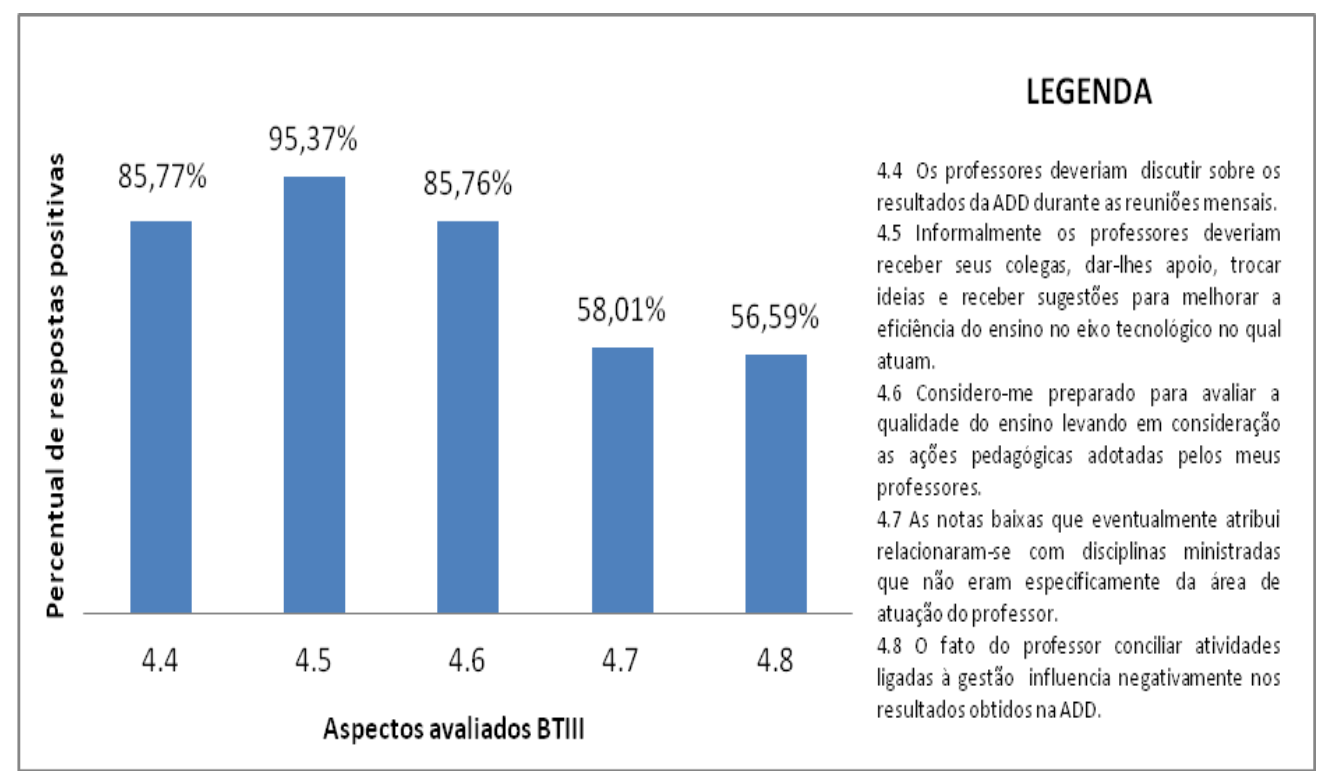

Figura 11. Asserções positivas na avaliação discente sobre o feedback individualizado para melhoria da prática docente

Fonte: Elaboração própria.

Ocorre que, apesar da redução de carga horária garantida pela resolução acima citada, ainda assim os professores que assumem cargo de gestão passam a enfrentar dificuldades em conciliar as atividades inerentes à docência com atividades de cunho administrativo, 
haja vista estas terem uma dinâmica diferenciada. Depreende-se que possa estar assente nessa característica a divergência de opinião observada entre professores e alunos, uma vez que o feedback fornecido semestralmente ao docente possibilita uma análise comparativa dos seus resultados com os demais ciclos avaliativos vivenciados. Já a perspectiva do aluno com relação ao desempenho do professor poderá limitar-se ao semestre em curso, ao qual encontra-se vinculado. Nas figuras 11 e 12, visualizam-se as asserções positivas dos respondentes.

Na análise das variáveis 4.4 e 4.5, observou-se confluência no que tange à inserção de um espaço de discussão sobre os resultados da ADD nas reuniões mensais promovidas pelas coordenadorias de eixo tecnológico (alunos: 85,77\%; professores: 64\%) e à existência do hábito entre os professores de trocarem experiência com seus pares com vistas a melhorar a eficiência do ensino no âmbito do eixo tecnológico no qual atuam (alunos: 95,37\%; professores: $84 \%$ ).

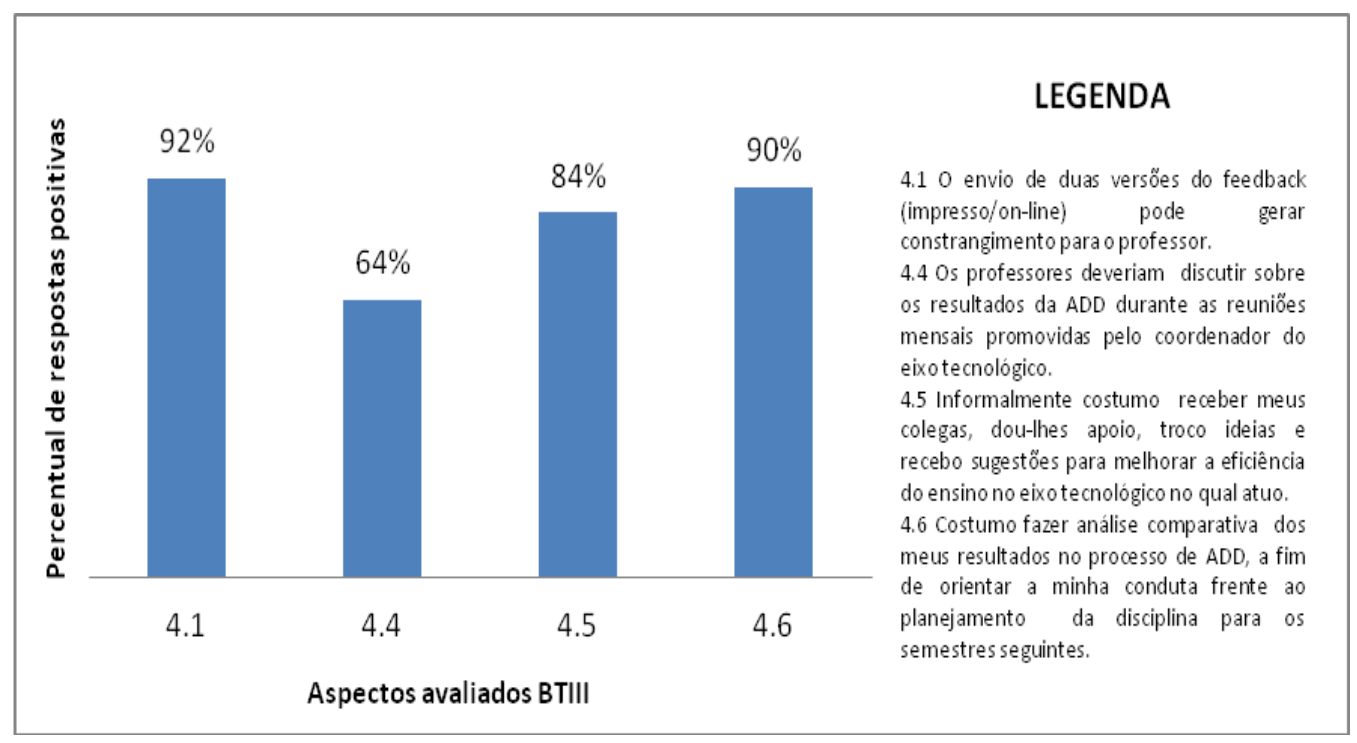

Figura 12. Asserções positivas na avaliação docente sobre a influência do feedback individualizado para melhoria da prática docente Fonte: Elaboração própria.

As variáveis 4.1 e 4.6, expressas na figura 12, correspondem, respectivamente, à possibilidade do feedback impresso, fornecido semestralmente aos docentes, gerar constrangimento e se os professores costumam fazer uma análise comparativa dos resultados da ADD para orientar suas condutas frente ao planejamento da disciplina para os semestres seguintes. Apurou-se que 92\% dos educadores valoraram positivamente o fato de receberem feedback impresso no início de cada semestre letivo com os resultados do semestre anterior. Embora os alunos tenham apresentado opinião divergente (item 4.1 figura 9), é relevante o valor atribuído pelo corpo docente à prática adotada. O mesmo constatou-se na variável 4.6, onde $90 \%$ dos professores concordaram com a assertiva de que costumam fazer análise comparativa a partir dos resultados recebidos.

Nos resultados obtidos, destacaram-se as seguintes expectativas dos envolvidos na ADD no que concerne à influência do feedback: (i) inserir a autoavaliação dos docentes nos ciclos avaliativos realizados, uma vez que estes têm como única fonte de informação a 
opinião dos alunos; (ii) criar espaço de discussão acerca dos resultados da ADD nas reuniões mensais promovidas pelas coordenadorias de eixo tecnológico; (iii) incentivar o corpo docente a realizar avaliações no âmbito das disciplinas ministradas independentemente dos ciclos avaliativos institucionais.

\subsection{Vínculo entre o processo avaliativo e as decisões institucionais}

De acordo com a figura 13 , observou-se a confluência de opiniões na perspectiva dos professores e dos alunos nas variáveis 5.2, 5.3, 5.4, 5.5 e 5.7.

Constatou-se que $91,88 \%$ (item 5.3 ) da amostra discente e $56 \%$ dos docentes consideram ineficiente a atual prática da instituição de apenas divulgar os resultados da ADD sem que haja um espaço de discussão para que as possibilidades de melhoria do ensino sejam planejadas. Para aproximadamente $58 \%$ (item 5.2) dos respondentes, a cultura de avaliar o desempenho docente semestralmente caracteriza-se como limitada, já que não são percebidas as consequências oriundas desse processo na unidade analisada. Embora na análise da variável 5.1 (figura 14) esteja evidente a valoração positiva atribuída pelos respondentes aos ciclos da ADD como algo consolidado na cultura da IES em estudo, ainda assim constatou-se, diante dos resultados demonstrados na figura 13, a existência de fragilidade no que concerne à cultura avaliativa.

Cerca de $90 \%$ (item 5.4) dos entrevistados consideraram que sucessivos resultados negativos nas avaliações semestrais deveriam acarretar em um efetivo acompanhamento do trabalho docente. O mesmo foi constatado na assertiva do item 5.5 , onde $85,76 \%$ dos discentes e $52 \%$ dos docentes concordam que os resultados da ADD deveriam ser usados para orientar os processos de escolha dos coordenadores de eixo tecnológico.

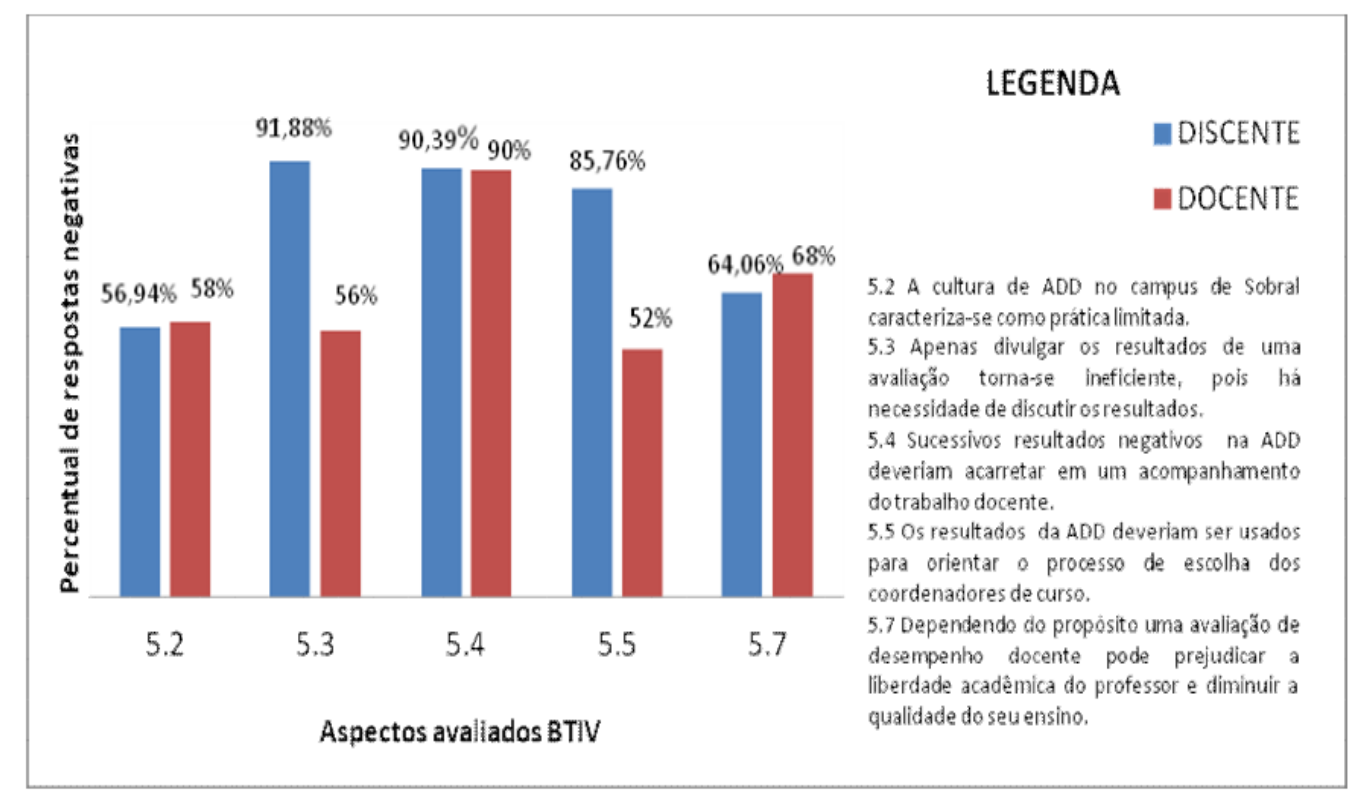

Figura 13. Asserções negativas na avaliação discente e docente quanto ao vínculo entre o processo avaliativo e as decisões institucionais Fonte: Elaboração própria.

Os resultados obtidos nas variáveis 5.4, 5.5 e 5.6 tornam patente a fragilidade do modelo de ADD em análise, pois a falta de evidências que apontem para a existência de vínculos entre as decisões institucionais referendadas nos resultados gerados pelos oito ciclos 
avaliativos, expressos na perspectiva dos envolvidos na avaliação, pode impedir a efetiva consolidação do programa de avaliação iniciado em 2009, uma vez que é essencial a existência de comunicação, comprometimento organizacional e colaboração (Stronge, 2010). Ocorre que a confiança torna-se base indispensável para que o diálogo em torno dos resultados de uma avaliação amplie as possibilidades de melhoria da qualidade do ensino, sem a qual há o risco de tornar inócua toda a avaliação.

A assertiva do item 5.7 investigou se, dependendo do propósito, uma ADD pode prejudicar a liberdade acadêmica do professor e diminuir a qualidade do seu ensino. Em média, $66 \%$ dos respondentes discordaram da afirmativa, fato que possibilita depreender que uma parte significativa dos professores e da amostra discente subestimam os riscos existentes em torno de sistemas de avaliação de desempenho docente quanto a seus propósitos. Há que se considerar, na análise dessa variável, que os respondentes têm como referencial a experiência vivenciada na IES em foco (uma ação interna de avaliação) e que, paradoxalmente, as fragilidades/expectativas identificadas nos blocos temáticos I, II e III provavelmente contribuíram para a perspectiva dos respondentes neste aspecto.

A variável 5.6, expressa na figura 14, investigou se existia urgência em se implantar um programa de apoio formal para os professores com consecutivos resultados negativos na ADD. Constata-se que, em média, $72 \%$ dos entrevistados concordaram com a assertiva do item 5.6. Portanto, referendando-se nos resultados obtidos, foram identificadas as seguintes expectativas dos envolvidos na $\mathrm{ADD}$, no que concerne às decisões institucionais: (i) implementar formas de comunicação com os envolvidos na ADD como meio de assegurar o comprometimento organizacional das lideranças e, assim, manter a confiança dos envolvidos no processo de avaliação até então vivenciado; (ii) implantar um programa de apoio para os docentes com sucessivos resultados negativos na ADD; (iii) utilizar os resultados da ADD como um dos critérios para a escolha dos coordenadores de eixo tecnológico.

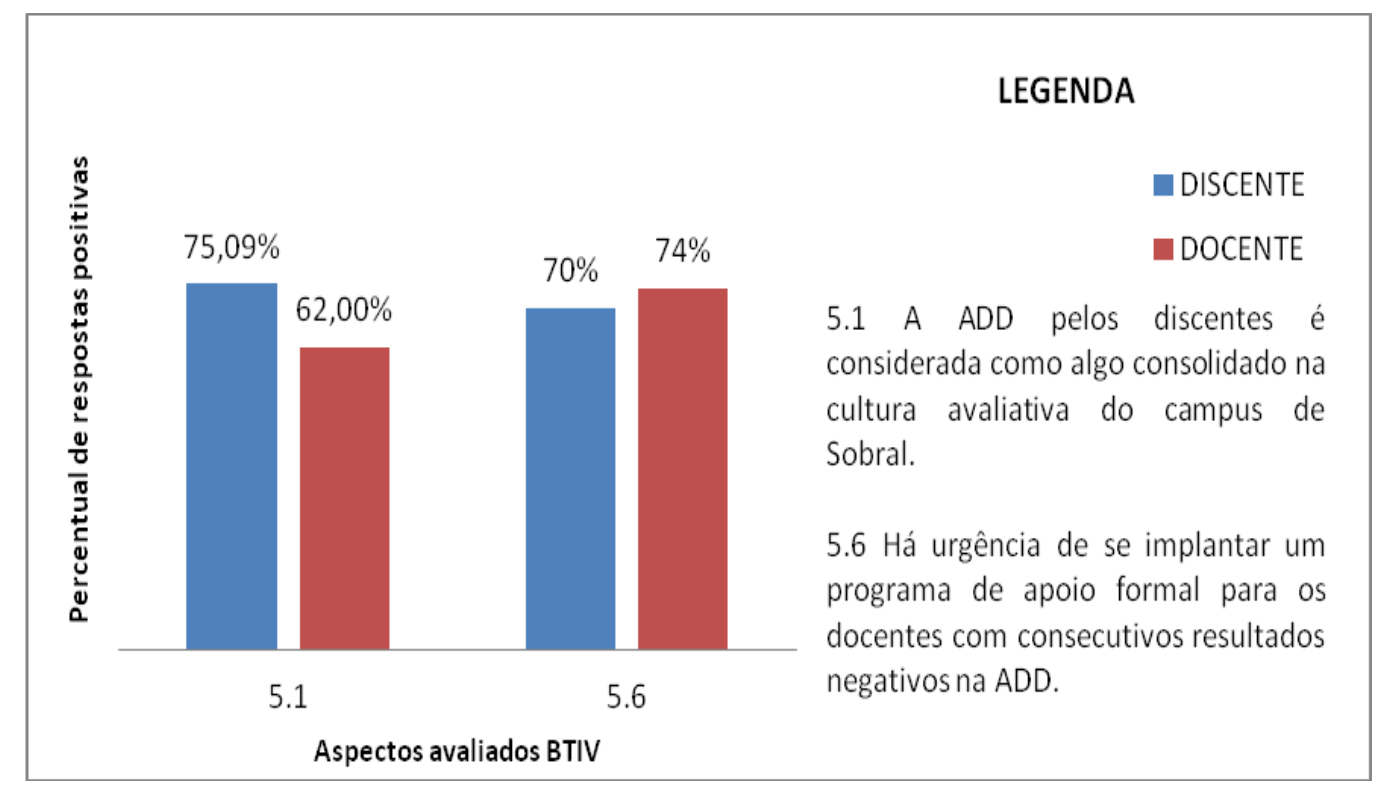

Figura 14: Asserções positivas na avaliação discente e docente quanto ao vínculo entre o processo avaliativo e as decisões institucionais

Fonte: Elaboração própria. 


\section{Conclusão e trabalhos futuros}

O presente trabalho apresentou um estudo sobre a avaliação docente, com o objetivo de analisar as expectativas de alunos, professores e gestores no processo de avaliação de desempenho docente no ensino superior, focando no uso dos resultados avaliativos para o aprimoramento do ensino. Foi realizado um estudo de caso em uma instituição federal de ensino, onde os resultados foram promissores, contribuindo para o estado da arte na pesquisa sobre avaliação institucional, por meio da análise das expectativas dos envolvidos no processo de avaliação de desempenho docente.

Em relação à divulgação dos resultados da avaliação, constatou-se, por meio das asserções negativas obtidas nas respostas dos alunos e docentes, que as formas usadas para divulgar os resultados da ADD (feedback individualizado e relatórios anuais por eixo tecnológico direcionado aos gestores) não tem produzido os efeitos desejados, já que $56,94 \%$ da amostra discente desconhece as formas utilizadas pela instituição para divulgar os resultados da avaliação, enquanto $72 \%$ dos docentes conhece apenas o feedback individualizado. Portanto, há o indicativo de que os relatórios supramencionados não têm sido utilizados para municiar ações/redirecionamentos no âmbito das coordenadorias de eixo tecnológico, passando, assim, a assumir apenas o papel de um repositório de informações. O fato de a comunidade acadêmica não conhecer as formas usadas para divulgar os resultados da ADD revelaram, sobretudo, limitação na percepção dos envolvidos na avaliação quanto à finalidade dos oito ciclos avaliativos até então vivenciados, assim como demonstraram a urgência de se adotar medidas corretivas no que diz respeito à comunicação, pois, como assevera Stronge (2010), trata-se de um dos componentes essenciais para o sucesso de qualquer sistema de avaliação de desempenho.

Evidenciou-se que a ADD do IFCE - campus de Sobral, pauta-se em ciclos avaliativos de caráter somativo, uma vez que ocorrem apenas no final do semestre letivo, fato que impede o redirecionamento da ação docente durante o processo de ensino-aprendizagem. Revelou-se, ainda, anseio da parte dos respondentes por uma perspectiva formativa de avaliação, fato que poderia minimizar os vieses identificados nas asserções negativas dos alunos e docentes, considerando que estes apontaram o desempenho dos estudantes na disciplina e a utilização dos fatos mais recentes ocorridos na sala de aula como fatores de influência durante a realização da avaliação dos professores (variáveis 3.2 e 3.3, nos figuras 7 e 8 , respectivamente).

É patente a necessidade de reformular o questionário usado na ADD da IES em estudo, já que, na opinião docente, os itens do questionário são amplos e podem motivar os estudantes, por uma falha no instrumental, a usar a empatia como único critério no momento da avaliação do professor. Apesar da divergência de opiniões entre os respondentes, é relevante mencionar que na avaliação do item 3.8 (figuras 9 e 10) encontra-se latente a importância da relação professor-aluno, uma vez que os resultados revelaram percepção dos professores em relação à existência de tendenciosidades, circunstância que reforçaria ou aumentaria a possibilidade de os estudantes influenciarem-se pela empatia no momento da avaliação docente.

Em relação ao contexto de trabalho do professor, o exercício da docência compreende a necessidade de corresponder às solicitações dos alunos, dos pares, da gestão institucional e da sociedade. Nesse sentido, não há como afirmar que um único instrumento de 
avaliação de desempenho é, ou não, capaz de refletir o contexto em que se realiza o trabalho do professor, embora, em média, $78 \%$ (item 3.7 - figuras 9 e 10) dos respondentes tenham concordado que os itens do questionário usado na ADD contemplam os pontos principais do trabalho docente. Ademais, o ensino e a aprendizagem estão em constantes transformações " [...] alterando-se os conteúdos, as condições em que são produzidas, num espaço de consentimento e disputas em que emoções, valores, opções e estilos pessoais se misturam com a racionalidade da disciplina científica [...]” (Sobrinho, 2011, p. 64).

Referendando-se nas divergências de opiniões (variável 4.7, 4.8 e 4.9 - figura 12), pode-se mencionar que os efeitos do feedback individualizado, fornecido aos professores semestralmente, apresenta restrições, pois constatou-se que parte do corpo docente percebe com desconfiança avaliações de desempenho baseadas unicamente na opinião de estudantes. Esse resultado pode indicar uma necessidade de se aprofundar o estudo que envolve a avaliação dos professores pelos alunos, em função dessa desconfiança.

Embora os educadores da unidade de ensino analisada tenham reconhecido os estudantes como uma importante fonte de informação acerca do trabalho docente, ainda assim revelaram que não consideram os alunos preparados para avaliar a qualidade do ensino levando em consideração as ações pedagógicas adotadas pelos professores no processo de ensino-aprendizagem. Na perspectiva dos envolvidos na ADD, outras audiências devem ser consideradas relevantes para retroalimentar a prática docente, como, por exemplo, os alunos e a autoavaliação, juntos, valorados pelos entrevistados como fontes significativas de informação.

O fato de os professores não comentarem com os alunos sobre o feedback individualizado recebido acerca dos resultados da ADD (variável 4.2) reforça a depreensão de que há urgência de se repensar a perspectiva de avaliação (somativa) atualmente adotada. Assim, é possível mencionar que o proveito do feedback reside no fato de os docentes valorarem a existência deste e de concordarem que fazem análises comparativas com as versões impressas fornecidas no início de cada semestre letivo, muito embora as limitações existentes na atual experiência da instituição obstaculizem a influência do feedback individualizado para uma efetiva melhora da prática docente.

Apesar da ADD em foco ancorar-se na finalidade precípua de retroalimentar a prática docente, e com isso contribuir com a gradativa melhoria do ensino do professor avaliado, evidenciou-se que o atual modelo não possui vínculo com as decisões institucionais, uma vez que não foi constatada, nem na perspectiva dos respondentes, nem na análise dos documentos institucionais, qualquer evidência que apontasse para a existência do efetivo uso dos resultados avaliativos para municiar decisões pedagógicas e/ou institucionais.

Enfim, apontar nesta pesquisa os aspectos frágeis observados na avaliação de desempenho docente experimentado pela IES em questão não representa a ideia de considerá-lo como falho, mas, sobretudo, que faz-se necessário pensar em medidas corretivas voltadas para o atendimento das expectativas identificadas. Além disso, “[...] uma avaliação deve ter flexibilidade suficiente para atender à diversidade dos interesses das suas várias audiências, com as expectativas das mais diversas possíveis" (Vianna, 2000, p. 75). Entre as ameaças à validade da presente pesquisa, pode-se citar a dificuldade de generalização de resultados, pelo fato do estudo de caso ter sido realizado em uma IES. Apesar das limitações, os resultados se apresentaram promissores, 
contribuindo para subsidiar o processo de avaliação e desdobramento, nas avaliações de desempenho dos docentes nas IES.

Como trabalhos futuros, pretende-se repetir o estudo em outras unidades da mesma instituição ou de outras instituições de ensino federais e particulares.

\section{Referências}

Alcaraz N., Fernández Navas, M. e Sola M. (2012). La voz del alumnado en los procesos de evaluación docente universitaria. Revista Iberoamericana de Evaluación Educativa, 5(2), 2639.

Amaral, N. C. (2009). Expansão-avaliação-financiamento: Tensões, desafios da vinculação na educação superior brasileira. Em D. Mancebo (Org.), Reformas da educação superior: Cenários passados e contradições do presente (pp. 113-146). São Paulo: Xamã.

Andriola, C. G. (2011). Avaliação dos docentes de instituições de ensino superior (IES): O caso da Faculdade Cearense (FAC). (Dissertação, Universidade Federal do Ceará, POLEDUC, Fortaleza). Disponível em http://www.repositorio.ufc.br:8080/ri/bitstream/123456789/2790/1/2011_dis_CGAndr iola.pdf

Andriola, W. B. (1999). Evaluación: La vía para la calidad educativa. Avaliação e Políticas Públicas em Educação, 7(25), 355-368.

Andriola, W. B. (2012). Avaliação do aprendizado discente: Estudo com professores de Escolas Públicas. Educar em Revista, 46, 141-158. doi:10.1590/s0104-40602012000400011

Andriola, W. B., Andriola, C. G., Lima, A. S. e Silva, J. C. (2012). Desenvolvimento de um protótipo de sistema informatizado para avaliação da atuação do docente universitário: Apresentação de resultados parciais. Revista Iberoamericana de Evaluación Educativa, 5(2), 198-216.

Bisquerra, R. (2004). Metodología de la investigación educativa. Madrid: La Muralla.

Bertolin, J. C. G. (2009). Avaliação da educação superior brasileira: Relevância, diversidade, equidade e eficácia do sistema em tempos de mercantilização. Avaliação Campinas. Sorocaba, $14(2), 351-383$.

Cavalcante, S. M. A., Cavalcante, L. M. S. e Andriola, W. B. (2010). Gestão estratégica do conhecimento nas instituições federais de ensino superior: Práticas facilitadoras. Em T. V. Viana (Org.), Múltiplas dimensões em avaliação educacional (pp. 47-79). Fortaleza: Imprece.

Cisneros-Cohernour, E. J. e Stake, R. E. (2010). La evaluación de la docencia en educación superior: De evaluaciones basadas en opinions de estudiantes a modelos por competencias. Revista Iberoamericana de Evaluación Educativa, 3(1), 219-231.

Cisneros-Cohernour, E. J. e Stake, R. E. (2012). Using evaluation results for improving teaching practice: A research case study. Revista Iberoamericana de Evaluación Educativa, 5(2), 40-51.

Fernandes, S. e Flores, M. A. (2012). A docência no contexto da avaliação do desempenho no ensino superior: Reflexões no âmbito de um estudo de caso. Revista Iberoamericana de Evaluación Educativa, 5(2).

Flick, U. (2009). Introdução à pesquisa qualitativa. Porto Alegre: Artmed.

Flores, M. A. (2009). Da avaliação de professores: Reflexões sobre o caso Português. Revista Iberoamericana de Evaluación Educativa, 2(1), 239-256. 
Gil, A. C. (2009). Como elaborar projetos de pesquisa. São Paulo: Atlas.

Graça, A., Duarte, P. A., Lagartixa, C., Tching, D. e Tomás, I. (2011). Avaliação do desempenho docente: Um guia para a ação. Lisboa: Lisboa Editora.

Hadji, C. A. (2010). Avaliação de professores em França: Da inspeção ao acompanhamento pedagógico. Em M. A. Flores (Org), A avaliação de professores numa perspectiva internacional: Sentidos e implicações (pp. 114-139). Porto: Areal.

IFCE. (2010). Conselho Superior. RESOLUÇÃO $N^{\circ}$ 34. Aprova o Regulamento da distribuição da carga horária de pesquisa, ensino e extensão. Fortaleza.

Lavor, J. F., Andriola, W. B. e Lima A. S. (2015). Avaliando o impacto da qualidade da gestão acadêmica no desempenho dos cursos de graduação. Um estudo em Universidade pública Brasileira. Revista Iberoamericana de Evaluación Educativa, 8(2), 233-254.

Lima A. S. e Andriola W. B. (2013). Avaliação de práticas pedagógicas inovadoras em curso de graduação em sistemas de informação. REICE. Revista Iberoamericana Sobre Calidad, Eficacia y Cambio en Educación, 11, 104-121.

Lima A. S., Andriola, W. B. e Tavares, W. A. (2015). Melhorando o processo de ensino e aprendizado em cursos de graduação na área de computação por meio da utilização de edublogs. Revista Ibero-Americana de Estudos em Educação, 10, 816-841.

Malhotra, N. (2011). Pesquisa de marketing: Foco na decisão. São Paulo: Pearson Prentice Hall.

Murillo, F. J. (2006). Carrera y evaluación del desempeño docente. Um estúdio comparado entre 50 países de América y Europa. Santiago de Chile: OREALC/UNESCO.

Ristoff, D. I. (2011). Avaliação institucional: Pensando princípios. Em N. C. Balzan e D. J. Sobrinho (Orgs.), Avaliação intitucional: Teorias e experiências (pp. 37-51). São Paulo: Cortez.

Santo, E. E. e Santos, F. M. G. (diciembre, 2010). Avaliação de desempenho docente: Um estudo de caso numa instituição de ensino superior privado em Salvador-Bahia, Brasil. Em X Coloquio Internacional sobre Gestión Universitaria en América del Sur, Mar del Plata. Disponível em http://www.inpeau.ufsc.br/wp/wp-content/BD_documentos/coloquio 10/190.pdf

INEP (2004). SINAES-Sistema Nacional da Educação Superior. Da concepção à regulação. Brasília: INEP.

Stake, R. E. (2008). La ventaja de los criterios, la esencialidad del juicio. Revista Iberoamericana de Evaluación Educativa, 1(3), 19-27.

Stronge, J. H. (2010). O que funciona, de facto, na avaliação de professores: Breves considerações. Em M. A. Flores (Org). A avaliação de professores numa perspectiva internacional: Sentidos e implicações (pp. 24-43). Porto: Areal.

Sobrinho, J. D. (2011). Avaliação institucional, instrumento da qualidade educativa: A experiência da Unicamp. Em M. A. Flores (Org), Avaliação institucional: Teorias e experiências (pp. 5386). São Paulo: Cortez.

Sobrinho, J. D. (2011). Universidade: Processos de socialização e processos pedagógicos. Em M. A. Flores (Org), Avaliação institucional: Teorias e experiências (pp. 15-36). São Paulo: Cortez.

Vaillant, D. (2008). Algunos marcos referenciales para la evaluación del desempeño docente em América Latina. Revista Iberoamericana de Evaluación Educativa, 1(2), 7-22.

Vianna, H. M. (2000). A avaliação educacional: Teoria-planejamento-modelos. São Paulo: IBRASA. 


\section{Breve CV de los autores}

\section{Ana Cléa Gomes de Sousa}

Mestre em Políticas Públicas e Gestão da Educação Superior pela Universidade Federal do Ceará (UFC). Especialista em Metodologia de Ensino Fundamental e Médio e Graduada em Pedagogia, pela Universidade Estadual Vale do Acaraú (UVA). Servidora efetiva do Instituto Federal de Educação, Ciência e Tecnologia do Ceará - Campus Sobral, no cargo de Pedagoga. Tem experiência na área de educação, como professora da educação básica com ênfase em Coordenação Pedagógica e Direção Escolar. Atua na Educação Profissional e Tecnológica como Pedagoga e Coordenadora TécnicoPedagógica de Cursos Técnicos e de Graduação no IFCE - Campus de Sobral. E-mail: anacleasousa@gmail.com

\section{Wagner Bandeira Andriola}

Possui graduação em Psicologia pela Universidade Federal da Paraíba (1990), especialização (lato sensu) em Psicometria pela Universidade de Brasília (1992), mestrado em Psicologia pela Universidade de Brasília (1993 - bolsista CNPq) e doutorado em Filosofia e Ciências da Educação pela Universidad Complutense de Madrid (2002 - bolsista CAPES). Atualmente é Professor Associado da Universidade Federal do Ceará (UFC), Coordenador de Avaliação Institucional (UFC), Editor-Chefe da Coleção Temas em Avaliação Educacional, do Programa de Mestrado e Doutorado em Educação (UFC) e Bolsista de Produtividade em Pesquisa (CNPq). Tem experiência nas áreas de Psicologia e de Educação, com ênfase em Avaliação de Sistemas, Instituições, Planos e Programas Educacionais, atuando principalmente nos seguintes temas: avaliação institucional, avaliação psicológica, psicometria e avaliação de programas e projetos sociais. Consultor ad-hoc da Revista Ensaio: Avaliação de Políticas Públicas em Educação (CESGRANRIO), da Revista Psicologia: Reflexão e Crítica (UFRGS), da Revista de Avaliação Psicológica (IBAP) e da Revista Psicologia: Teoria e Pesquisa (UnB); Consultor ad hoc do Conselho Nacional de Desenvolvimento Científico e Tecnológico (CNPq), da Coordenação de Aperfeiçoamento de Pessoal de Nível Superior (CAPES), da Fundação Cearense de Apoio Científico e Tecnológico (FUNCAP). Membro da Diretoria da Associação Nacional de Avaliação Educacional (ABAVE - Gestões 2006/2007 e 2008/2009), da Red Iberoamericana de Investigación sobre Cambio y Eficacia Escolar (RINACE) e do Grupo de Trabalho para Elaboración de Estandares y Evaluación del Programa de Promoción de la Reforma Educativa de América Latina y el Caribe (PREAL). Ex-bolsista de Desenvolvimento Científico e Regional (DCR) do CNPq. E-mail: w_andriola@ufc.br

\section{Alberto Sampaio Lima}

Doutor em Engenharia de Teleinformática pela Universidade Federal do Ceará. Mestre em Informática Aplicada pela Universidade de Fortaleza. Bacharel em Ciência da Computação pela Universidade Estadual do Ceará. Tem experiência na área de Ciência da Computação, com ênfase em Arquitetura de Sistemas de Computação, atuando principalmente nos seguintes temas: Gestão de Tecnologia da Informação e Comunicação, Redes de Computadores, Engenharia de Software, Novas Tecnologias na 
Educação, Avaliação da Educação. Professor do Mestrado Profissional em Políticas Públicas e Gestão da Educação Superior da Universidade Federal do Ceará (POLEDUC).E-mail: albertosampaio@ufc.br 